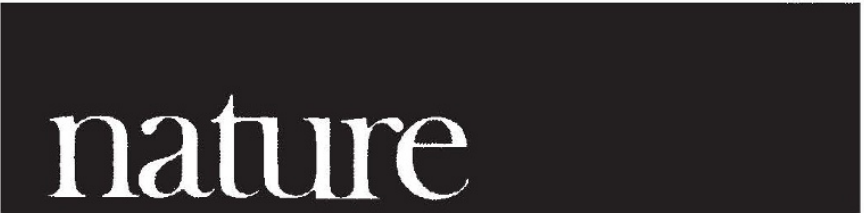

Volume 250

\section{Medical policymaking in Britain}

IF there is any subject that is guaranteed to generate boredom amongst scientists it is science policy. The average practitioner believes, with some justification, that whereas it would be most undesirable for a country to eschew a defence policy and leave all decisions, from procurement to strategy, to the soldier in the field, the scientist should be immune from policy constraints.

This system, in which the majority of scientists have received the majority of what they asked for and have in general been answerable only to their own consciences and to a relatively genial sponsor, is beginning to crumble as the growth rates for expenditure on research drop dramatically and as the demand for accountability rises sharply. Within the next year or two many scientists will indeed discover that there is such a subject as science policy, and arid and irrelevant as it may have seemed in the past, it is science policy that will decide whether their project will continue to be funded. The recent publication of the Medical Research Council's Annual Report (HMSO, 97p) is an appropriate time to look at the policymaking machinery in the biomedical field, and the report is generous in its attention to policy. The council is still able to say that "the ideas and interests of the individual scientists at the bench are the driving force behind science", although it adds in the next sentence "there may also need to be active discouragement of over-populated but low priority areas"-a fairly evenhanded way of mixing good and bad news.
And yet there is something strangely and almost intangibly missing from the report. It is most easily seen in the section describing progress in research on selected topics. One gets the unmistakable impression that the Medical Research Council is the last bastion the world has against disease and death. The report is of course addressed primarily to the Secretary of State for Education and Science (who is told in the second paragraph of the transmittal that for $£ 1.00$ he can buy the council's Handbook from headquarters), and as such necessarily must remark on the successes that government money has bought. Nevertheless there remains just the vaguest feeling throughout the policy section that this is policy for medical research determined by the Medical Research Council without mention of the fact that a quite substantial amount of research is done by other research councils, by charities and trust funds, and by the pharmaceutical industry. Of course, excellent liaison may exist, although it doesn't shine through. And it is obviously desirable to allow a multiplicity of funding sources to exist so that power does not reside solely in one council, however appointed. But if it is indeed the function of the MRC to promote the balanced development of medical and related biological research and if all research programmes are going to fall on harder times in the next year or two it would be good to know that policymaking reflects the 'mixed economy' nature of Britain's support of medical science.

\section{Dear Mr Turner ...}

By August 1 you had hoped to have appointed several research fellows to pursue fundamental biological research. Instead, as everyone now knows, you came into conflict during the selection procedure with potential recipients of the awards who objected to your refusal to consider those who had religious beliefs of one kind or another. No doubt you feel sore at all this and believe that there are fundamental inconsistencies between religion and science which cannot be glossed over by research scientists.

You are by no means alone in your doubts that the pursuits of science and religion are incompatible occupations; indeed I suspect that amongst businessmen it may be a majority view. Of course, there are many scientists whom you would probably happily exclude from your strictures - those working in agriculture, medicine, materials and so on are presumably exempt, but you would probably wish to retain those subjects which move close to the problems of man and the universe, such as astronomy, geology and those branches of biology that are concerned with the nature of life. How, you might say, could someone dare to contemplate an idea in these fields which struck at his own personal convictions.

As you know, there have been scientists of great distinction who have held very strongly to religion and, one suspects, many more who have believed in some underlying purpose to the universe without feeling that they had to devote an hour to it every Sunday. Perhaps some were inhibited from peeping too far behind the scenes, although I know of none, but many more were positively driven on by their beliefs to understand more about a universe at which they marvelled.

Furthermore successful scientists learn flexibility early in their training-they cannot afford to become too committed to conventional wisdom because they are there to discover, not to reinforce. Thus they are unlikely to hold fast to any religious beliefs with which they know their research might bring them into conflict. They are also pragmatic and like fame as much as anyone else, so they are not going to stand by for the sake of religious beliefs whilst someone else finds a cure for cancer or a recipe for longevity.

Most scientists would have found it extraordinarily difficult from their personal experiences in the fields I have mentioned to categorise scientists as religious or otherwise from their mode of working and their approach to fundamental questions. You would probably have found the same. 